\title{
Open Access policies and Science Europe: State of play
}

\author{
Amanda Crowfoot \\ Director, Science Europe, Brussels, Belgium \\ E-mail: office@scienceeurope.org
}

\begin{abstract}
Increasing Open Access policy alignment may be observed among the members of Science Europe. Members typically have a mandatory policy that supports both the gold and the green road to open access, funds article-processing charges, and specifies maximally acceptable embargo periods for green open access.
\end{abstract}

Keywords: Open Science, Open Access, Open Access policy, Open Access monitoring, OA2020

\section{Who is Science Europe?}

Science Europe is the policy association of European public research funding and research performing organisations. It has 43 member organisations from 27 countries [1]. Its main roles are advocacy and interest representation; collaboration platform; and think-tank for science policy issues. Open Science and Open Access are among the strategic priorities.

What I would like to do, from the perspective of the national research organisations, is to report on Open Science and Open Access with regard to

- Policy,

- Capacity building,

- State of play.

\section{Science Europe policy}

The Science Europe 'Principles on the Transition to Open Access to Research Publications' were adopted in 2013 by all members, indicating the common principle of a transition to Open Access [2].

The 'Principles on Open Access Publisher Services' were adopted in 2015 by all members, setting out the minimum expected services by publishers [3].

Science Europe supports the policy aims of the OA2020 initiative; specifically,

- To transform the majority of journals from subscription to OA publishing in accordance with community-specific publication preferences;

- To convert resources currently spent on journal subscriptions into funds supporting sustainable OA business model;

- To invite universities, research institutions, funders, libraries, and publishers to collaborate on a transition for the benefit of scholarship and society at large. 


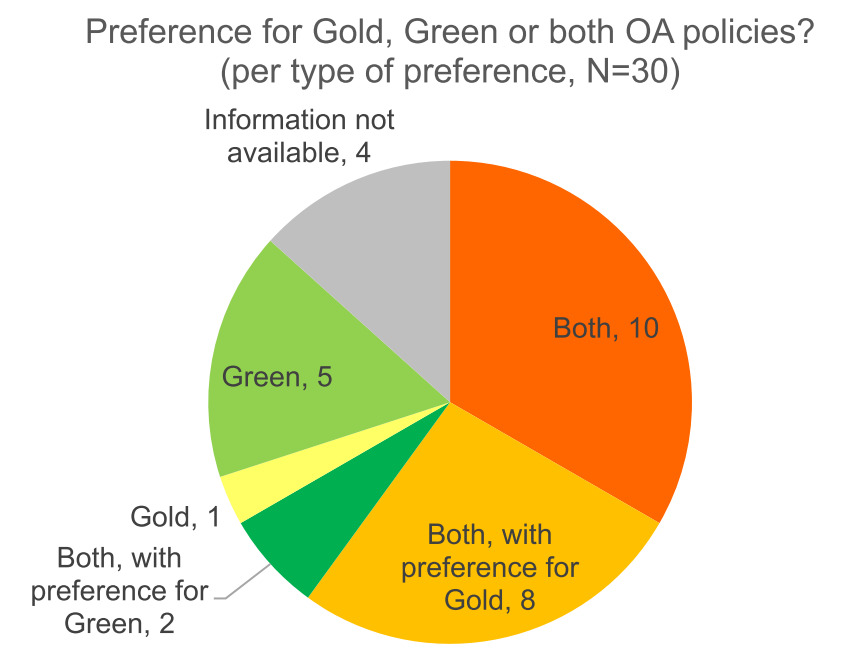

Fig. 1. Science Europe member organisations' preferred OA policy.

\section{Policy alignment}

In 2016, the Science Europe member organisation were surveyed. 30 members responded (Fig. 1). Of these, 26 members already had a published open access policy, and the remaining members were in the process of adopting a policy. Furthermore, in 2016

- 22 members had a mandatory policy,

- 18 members had embargoes of 6 months for STEM and 12 months for SSH, and

- 20 members supported both gold and green open access policies, albeit with variations (Fig. 1).

Notable is the open access policy alignment between Science Europe member organisations and the EU's Horizon 2020 programme's OA rules in terms of a mandatory policy, embargo periods, open access funds, and payment of article-processing charges.

\section{Capacity building}

A majority of Science Europe member organisations support article-processing charges. Typically, there is a dedicated open access fund (Fig. 2).

Many member organisations have conditions attached to the payment of article-processing charges. These vary widely and include:

- No double dipping, hybrid in the sense of offsetting only;

- Requirement from every institute belonging to the organisation to report in the evaluation procedure about its activities;

- Immediate Open Access, no embargo allowed;

- Permission to be given for the publication post-print to be deposited in repositories other than the publisher's own repository;

- Creative Commons CC-BY license (or equivalent) to be attributed to the publication;

- No restriction to its access or re-use is allowed. 


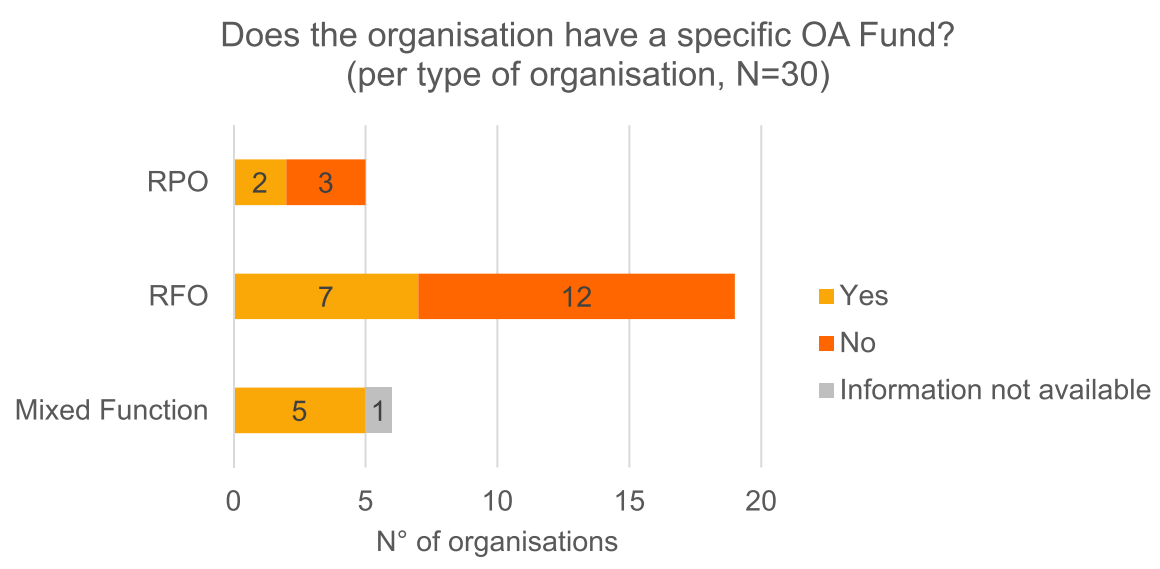

Fig. 2. Science Europe member organisations' OA funds.

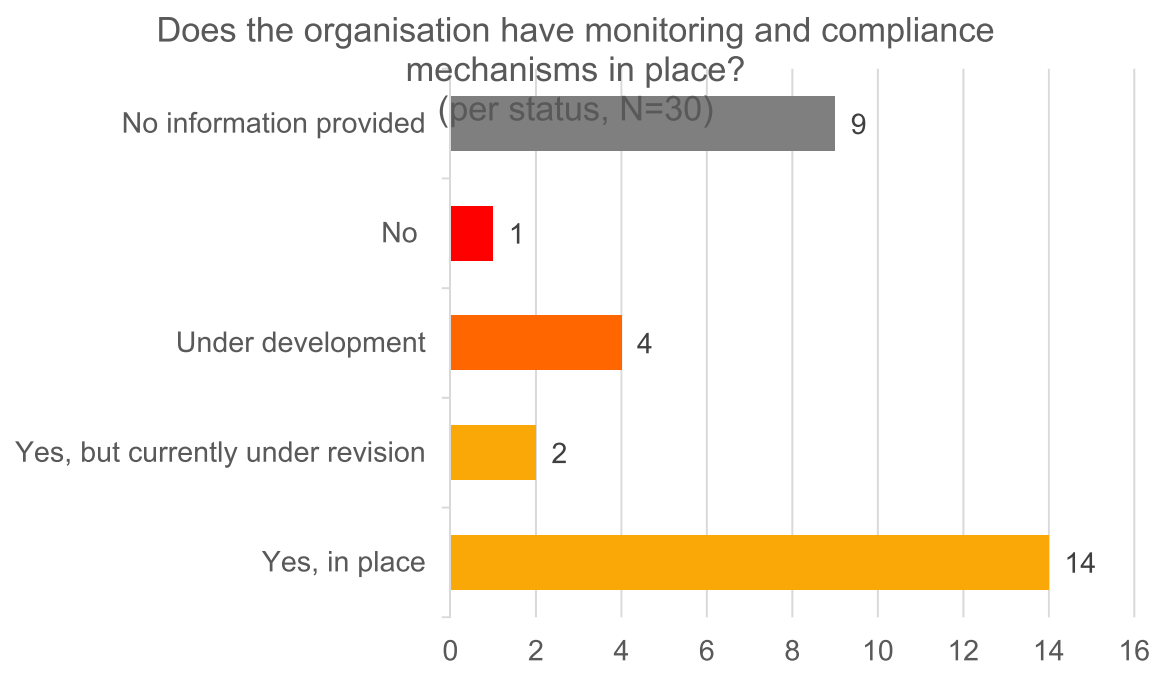

Fig. 3. Science Europe member organisations' OA compliance monitoring.

\section{State of play}

A particular challenge is the development of monitoring and compliance mechanisms for open access policies (Fig. 3)

Overall, the policy conditions to help public research funding and research performing organisations prepare and achieve the OA2020 goals are mostly in place.

Science Europe has contributed to preparing the ground for collective action of this type by providing common principles as well as a platform for exchanging practice and experience. Both Science Europe recommendations and OA2020 goals are in line with and support recent national and EU policy initiatives, including Conclusions of the Council of the EU that call for Open Access to be the default by 2020. 


\section{References}

[1] http://www.scienceeurope.org.

[2] http://www.scienceeurope.org/wp-content/uploads/2015/10/SE_POA_Pos_Statement_WEB_FINAL_20150617.pdf.

[3] http://www.scienceeurope.org/wp-content/uploads/2015/04/270415_Open_Access_New_Principles.pdf. 